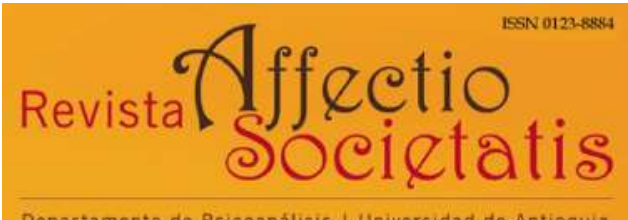

Departamento de Psicoanálisis | Universidad de Antioquia

Revista Affectio Societatis

Departamento de Psicoanálisis

Universidad de Antioquia

revistaaffectiosocietatis@udea.edu.co

ISSN (versión electrónica): 0123-8884

Colombia

2019

Bibiana Claudia Vangieri

AVATARES QUE ATRAVIESAN EL CUERPO Y SU RELACIÓN CON LA ÉPOCA. UNA MIRADA PSICOANALÍTICA

Revista Affectio Societatis, Vol. 16, N. ${ }^{\circ}$ 30, enero-junio de 2019 Art. \# 5 (pp. 97-116)

Departamento de Psicoanálisis, Universidad de Antioquia Medellín, Colombia 


\title{
AVATARES QUE ATRAVIESAN EL CUERPO Y SU RELACIÓN CON LA ÉPOCA. UNA MIRADA PSICOANALÍTICA
}

\author{
Bibiana Claudia Vangieri' \\ Universidad del Aconcagua, Argentina \\ bibianavangieri@ hotmail.com \\ ORCID: 0000-0003-1972-5784
}

DOI: 10.17533/udea.affs.v16n30a05

\section{Resumen}

El presente artículo es resultado de la tesis doctoral Avatares que atraviesan el cuerpo y su relación con la época. Una mirada psicoanalítica. La metodología de investigación utilizada fue de tipo cualitativa en el marco de un tipo de estudio descriptivo-interpretativo. La misma indaga acerca de diferentes avatares que atraviesan el cuerpo en la actualidad, tales como tatuajes, escarificaciones, perforaciones, autolesiones y

fenómenos psicosomáticos. Se trata de marcas que, a diferencia del síntoma, se manifiestan como otras formas de respuesta a la angustia, fenómenos que se resisten al decir, acontecimientos de cuerpo que implican un goce autístico, signos sobre el cuerpo opacos al sentido, marcas de lalengua.

Palabras claves: cuerpo, acontecimiento, goce, sinthome.

1 Licenciada en Psicología. Universidad del Aconcagua, Facultad de Psicología, Mendoza, 1995. Psicóloga Clínica. Otorgada por el Honorable Consejo deontológico. Ministerio de Desarrollo Social y Salud. Gobierno de Mendoza. Julio del 2003. Directora de Tesis de grado de alumnos de la carrera Licenciatura en Psicología. Facultad de Psicología. Universidad del Aconcagua. Mendoza. Año 2005 a la fecha. 


\section{VICISSITUDES GOING THROUGH THE BODY AND THEIR RELATION TO THE EPOCH. A PSYCHOANALYTIC PERSPECTIVE}

\section{Abstract}

This paper is a result of the doctoral thesis Vicissitudes Going through the Body and Their Relation to the Epoch. A Psychoanalytic Perspective. It used a qualitative methodology in the context of a descriptive-interpretative study. It explores the different vicissitudes currently going through the body, such as tattoos, scarifications, piercings, self-harms, and psychoso- matic phenomena. They are marks that, contrary to the symptom, manifest as other forms of response to anxiety, phenomena resisting the saying, body events entailing an autistic jouissance, signs on the body that are blurred to the sense, marks of lalangue.

Keywords: body, event, jouissance, sinthome.

\section{AVATARS QUI TRAVERSENT LE CORPS ET LEUR RAPPORT AVEC L'ÉPOQUE. UNE APPROCHE PSYCHANALYTIQUE}

\section{Résumé}

Cet article est issu d'une thèse de doctorat intitulée Avatars qui traversent le corps et leur rapport avec l'époque. Une approche psychanalytique. Dans le cadre d'une étude de type descriptif-interprétatif, l'on a employé une méthodologie qualitative. C'était l'outil utilisé pour enquêter sur les différents avatars qui traversent le corps aujourd'hui, tels que les tatouages, scarifications, piercings, blessures auto-infligées et phénomènes psycho- somatiques. Il s'agit de marques qui, contrairement au sinthome, se manifestent en tant que d'autres formes de réponse à l'angoisse, des phénomènes qui résistent au dire, des événements du corps qui comportent une jouissance autistique, des signes sur le corps opaques pour le sens, des marques de lalangue.

Mots-clés : corps, événement, jouissance, sinthome.

Recibido: 02/27/2018 • Aprobado:12/04/2018 


\section{Introducción}

En la clínica actual acuden sujetos con diferentes marcas en su cuerpo: tatuajes, perforaciones, escarificaciones, autolesiones, fenómenos psicosomáticos, que anuncian que allí hay un parlêtre (Lacan, 2006/1975), un cuerpo hablante.

Brodsky (2015) plantea: ¿por qué hablar de cuerpo en psicoanálisis, cuando su práctica parece poner el cuerpo en suspenso dando un lugar privilegiado a la palabra? Aunque casi no haya contacto físico, o por el uso del diván la mirada quede fuera..., no podemos prescindir del cuerpo. Incluso para hablar hace falta un cuerpo. Al paciente no sólo se le pide que hable, también se le pide que venga, que acuda de cuerpo presente, al igual que el analista. Los cuerpos no están ahí por casualidad, su presencia no es contingente. "Al consultorio se trae el cuerpo y se habla del cuerpo, del cuerpo propio y del cuerpo del Otro, con el que normalmente no se sabe qué hacer" (Brodsky et al., 2015, p.39).

Este cuerpo y sus malestares se hacen presentes en la clínica actual, es una clínica marcada por el acontecimiento de cuerpo. Lo real se manifiesta ahí despojado de toda envoltura significante. La clínica se presenta frecuentemente como un escaparate de goces aislados, privados de esa envoltura (Rollier et al., 2016).

Por su parte, Silvia Salman plantea: “(...) en relación al goce, la experiencia de análisis puede leerse como una experiencia de cuerpo" (2013, p.7). El psicoanálisis opera con la palabra, por lo cual se deberá pensar de qué modo se articulan palabra y cuerpo. En el Seminario 20, Aún, Lacan (1981/1972-1973) dirá que el parlêtre hablando goza; como plantea también Salman (2013), las palabras hacen cuerpo. El sujeto que va al análisis es un sujeto que sufre de cosas que le han dicho. Es un sujeto que está enfermo de las palabras del Otro, de ciertos enunciados. Estos encuentros originales con las palabras escriben marcas en el cuerpo e instalan un modo de gozar que deja al sujeto enganchado, de ahí en más, en una repetición (Salman, 2013). 
En estos modos de gozar, en estos avatares, se pone en funcionamiento un montaje pulsional. El término avatares está presente en las obras de Freud y de Lacan, asociado especialmente al concepto de pulsión, y a sus diferentes vicisitudes -puesto que no se trata en el sujeto de un programa pulsional, no se trata del destino, pues este implica fijación-, lo pulsional se caracteriza por lo variable:

Y, por otra parte, al hecho que la sublimación se sujeta esencialmente a la suerte, al avatar, a la 'schicksal' -vicisitud- de las pulsiones, que ella se refiere a esos avatares, lo que para Freud es anunciado en el artículo que tiene ese título: "Trieb und Triebschiksal", "pulsiones y sus avatares". (Lacan, 1981/1968-1969, p.127).

Así pues, lo pulsional se halla articulado a un trayecto. Por ello interesa destacar uno de los elementos, el objeto. Freud destaca en "Pulsiones y destinos de pulsión" (1915/1976) que se hablará de fijación cuando se establece un lazo íntimo entre la pulsión y el objeto. Entonces, la pulsión es lo más variable -por los avatares pulsionales-, pero a la vez es lo más fijo; una vez que cierto "programa" de goce se ha escrito, un encuentro que comienza como contingente puede devenir necesario. Aquel corte, tatuaje, perforación, que comienza como contingente puede devenir luego en una repetición, constituyendo una vía facilitada para el goce. Hay en ciertas marcas que se realizan sobre el cuerpo, un tratamiento real de la piel donde la pulsión se satisface. Cierta labilidad en el encadenamiento simbólico deja vía libre a otros modos de goce, alejándose del modelo metafórico del síntoma histérico.

Dichos avatares (Lacan, 1981/1968-1969) remiten, entonces, a vicisitudes pulsionales, trayectos que, de ser contingentes, pueden devenir en una repetición. Son del orden de una marca, no de una articulación entre significantes. Se trata de signos, efectos corporales del significante, escrituras a modo de jeroglíficos, enigmáticos, que se repiten, persisten, insisten; marcas que dan cuenta de un intento de inscripción fallido. Búsqueda de un significante que sea realmente tal, es decir, que pueda alojar al sujeto, que pueda representarlo para otro significante. Son marcas que intentan "hacer cuerpo" cuando faltan las palabras. 
Para ello la piel ocupa un lugar predilecto, un gran lienzo al que el sujeto percibe y vive como "un cuerpo". La piel "siente"; en ella se puede erigir nuevos bordes pulsionales. A modo de una banda de Moebius posee una extimidad, no está dentro ni fuera, zona erógena por excelencia, lugar privilegiado para lo pulsional.

\section{Un cuerpo para gozar}

En su obra, Lacan se refiere al concepto de cuerpo en diferentes momentos: como lugar del Otro, como un revestimiento imaginario y como lugar del goce:

En 1966 y en 1967 lo definirá como el lugar del Otro, pero no un otro con quien se tiene una relación intersubjetiva, sino un Otro que deja en el cuerpo cicatrices en los orificios del cuerpo. (Lacan, 1988/1966-1967). En 1967 en Intervenciones y textos 2 continuará sosteniendo que el cuerpo es "un lecho" para ese Otro, Otro que realiza sobre ese cuerpo una operación significante. (Lacan, 1988/1967).

Este concepto que repetirá en 1972 diciendo que ese cuerpo se corporiza de manera significante y agregando que esto implica un goce (Lacan, 1981/1972-1973). En 1966 y en 1985 también se referirá al goce, dirá que el cuerpo es más que una extensión, que está hecho para gozar, y aclara que es para gozar no en relación a otro, sino de sí mismo. (Lacan, 1985/1966).

En 1975 definirá al cuerpo como una bolsa que retiene órganos y destacará que este se lo siente como piel (Lacan, 2006/1975). Se presenta en esto al cuerpo como un revestimiento imaginario (bolsa) que cubre un real (órganos). En este mismo seminario sobre el sinthome hará referencia a que la relación del sujeto con ese cuerpo no es una relación simple y que además ese cuerpo tiene agujeros (Lacan, 2006/1975). Es decir, esa cubierta imaginaria no lo cubre todo. Dejará en claro, además, que el sujeto no es un cuerpo, sino que "lo tiene", destacando en esto la ajenidad del mismo (Lacan, 2006/1975). 


\section{Un "cuerpo hablante"}

“QQué es el cuerpo hablante? Ah, es un misterio" (Lacan, 1981/19721973, p.158, las cursivas son mías). "Lo real, diré, es el misterio del cuerpo que habla, es el misterio del inconsciente" (p.55, las cursivas son mías).

En 1975 propone el término parlêtre: neologismo que condensa parler (hablar) y être (ser), articulando así significante y cuerpo. Con esto no se refiere a que el cuerpo hable, aclara Bassols (Brodsky et al., 2015), es el sujeto el que se sirve del cuerpo para hablar: “(...) ese ser o ese cuerpo sólo lo son en la medida en que pueden hablar, en la medida en que el ser es un ser hablante o, incluso, un ser parlante (...)" (p.13). El cuerpo es más bien un parlante, entonces, es el ser quien habla con el cuerpo y se escucha por el parlante, un parlante como el lugar donde se escucha lo que se dice, siempre desde Otro lugar. No es que el cuerpo habla, sino que se habla con el cuerpo.

Lacan (1985/1966) ha definido al cuerpo como algo hecho para gozar. Este cuerpo no se define por su forma, por su imagen, sino por el hecho de estar habitado por el goce de lalengua (Brodsky et al., 2015). Miller (2011) acentúa esto refiriendo que ese cuerpo “(...) tiene consistencia de goce (...) eso goza allí donde eso no habla, donde no produce sentido" (p.107). Entonces surge la pregunta: si ese goce no produce sentido, si "no habla" ¿por qué hablar de un cuerpo hablante? Porque el cuerpo habla en términos de pulsiones y no de sentidos, tal como refiere Miller (Rollier et al., 2016). Y ¿cómo es que habla en términos de pulsiones?:

(...) las pulsiones son el eco en el cuerpo del hecho de que hay un decir. Para que resuene este decir, para que consuene (...) es preciso que el cuerpo sea sensible a ello. De hecho lo es. Es que el cuerpo tiene algunos orificios (...) (Lacan, 2006/1975, p.18).

Es decir, como refiere Bassols, algo "resuena" en el cuerpo por el hecho de tener zonas erógenas con bordes (Brodsky et al., 2015). 
En el Seminario 23, Lacan (2006/1975) privilegia un orificio corporal: la oreja, debido a sus características: no puede cerrarse, carece de párpados, labios o esfínter. Es a través de ese agujero que lalengua hace su intrusión en la carne, que las palabras afectan la sustancia gozante provocando que en el cuerpo algo responda, que haya un decir que resuene. Cuando se habla de goce, se trata de un goce más allá del principio del placer:

Afectado por el lenguaje el cuerpo está marcado por una satisfacción problemática y paradójica que desde siempre altera los límites de la homeostasis y desemboca en un goce que va más allá del placer. El exceso le es consustancial, pero reviste variadas formas. (Rollier et al., 2016, p.125).

Entre esas variadas formas encontramos ciertos acontecimientos de cuerpo, abordados algunos en este trabajo.

La noción de parlêtre viene -en la obra de Lacan- a ubicarse donde antes estaba el sujeto del inconsciente, concepto que tiene predominantemente una relación con el Otro del lenguaje, en tanto parlêtre es un concepto que suma a este sujeto la relación con el cuerpo, cuerpo en tanto sustancia gozante. El goce en juego tiene temporalidad y espacialidad; la temporalidad del goce es siempre la repetición, y la espacialidad es el lugar donde anida el goce, que no es otro que en el cuerpo (Miller et al., 2013).

Morao (Rollier et al., 2016) va a plantear que el propio cuerpo puede convertirse en un objeto, en un instrumento que, por medio de intervenciones singulares, permite al parlêtre tratar el goce sin ley. Miller (Rollier et al., 2016) aporta: "El signo recorta la carne, la desvitaliza y la cadaveriza, y entonces el cuerpo se separa de ella" (p.27).

Vittar (2014) enuncia: “Es el cuerpo que porta la huella del signo, el cuerpo superficie de una inscripción imposible de borrar, a la que se le inventó un querer decir cuando en verdad no quiere decir nada, sólo itera" (p.46). La iteración no es dialéctica, es repetición de un Uno solo, sin par, sin cadena, infértil al sentido. 


\section{Dimensiones del cuerpo}

Lacan va a plantear diferentes dimensiones del cuerpo que se enlazan entre sí, en un primer momento el cuerpo es ante todo la forma del cuerpo; mientras que en un segundo tiempo lógico, el cuerpo se encuentra afectado por el significante como una sustancia gozante. De este modo se puede hablar, en primer lugar, de un cuerpo imaginario, del espejo, un cuerpo reducido a su forma, el cuerpo visual, que se obtiene por la asunción de una imagen. Refiere Lacan que esto se acompaña de cierto júbilo y complacencia que señalan el control de la identificación especular. Dado que el sujeto se identifica en el otro, a partir de la imagen del otro, esto determina un efecto de alienación fundamental (Lacan, 2008/1966). El Yo se constituye a partir de la nueva acción psíquica que consiste en la identificación a la imagen unificada que aporta el semejante. El sujeto se hace representar por su cuerpo tomándolo como propio y unificado. Se asume una imagen cuya función es ortopédica y permite velar el cuerpo fragmentado, es decir, el cuerpo resulta un engaño. No hay imagen completa del cuerpo:

(...) el amor propio es el origen de la imaginación. El parlêtre adora su cuerpo porque cree que lo tiene. En realidad no lo tiene, pero su cuerpo es su única consistencia -consistencia mental, por supuesto, porque su cuerpo a cada rato levanta campamento. (Lacan, 1975/2006: 64).

La eficacia formadora de la imagen proporciona la idea de unidad del cuerpo, haciendo que los seres humanos adoren ese ideal de la buena forma. Esta forma otorga consistencia al ser hablante; es una suerte de bolsa de piel, imagen virtual que protege al sujeto de la fragmentación, de lo real del organismo. La imagen cohesiona lo que está disgregado y desajustado, montando la imagen especular (Rollier et al., 2016). Brodsky (2015) aporta que esa imagen es un tratamiento del goce del cuerpo: le da unidad, marco, límite; civiliza el goce del cuerpo a través de la ilusión de dominio del yo, pero al mismo tiempo esa imagen tiene efectos de goce sobre el cuerpo.

Pero también el cuerpo significantizado, en el que el goce queda contorneado por el significante. Es el cuerpo en el registro simbólico 
vaciado de ese goce primordial y trabajado por el lenguaje. Se constituye en un tiempo mítico en que la palabra muerde la carne y a partir de allí adviene un sujeto (Lacan, 1962-1963/2006). El efecto del lenguaje es la pérdida del cuerpo orgánico y, con ello, de las necesidades que se transforman en un hecho simbólico o cultural: "Las palabras no son evanescentes para los cuerpos: los marcan, dejan en ellos heridas, incisiones, huellas de un goce imborrable" (Rollier et al., 2016).

El cuerpo es lo que le permite al significante encarnarse, ofrece sus orificios como reductos para el goce que allí se condensa. El cuerpo no puede pensarse sin el Otro, los agujeros corporales son su marca (Castelluccio, 2013). Se trata del recorrido de las pulsiones, así construidas entre el cuerpo y el Otro del decir.

También Lacan se refiere a un cuerpo en relación a lo real, que incluye la dimensión del acontecimiento de cuerpo, un goce que no está localizado a partir de un significante y del que, por ello, se obtiene una satisfacción por fuera del sentido (Salman, 2013).

El cuerpo, en su dimensión Real, se presenta como lo imposible de ser imaginarizado o simbolizado. Es lalengua incrustada en la carne, como refiere Bassols (Brodsky et al., 2015), entendiendo lalengua como ese enjambre de S1. Allí surge el parlêtre, en el instante del misterio, del acontecimiento de la unión de lalengua con el cuerpo (Lacan, 1973-1974).

A partir de lo expuesto, cabe destacar que el cuerpo es fundamentalmente pulsional, y que el cuerpo imaginario es un semblante que vela esa fragmentación (Rollier et al., 2016).

\section{Sinthome: acontecimiento de cuerpo}

Del encuentro de lalengua con el cuerpo surge el acontecimiento de cuerpo. En el Seminario 23, El sinthome (2006/1975), Lacan hará referencia al mismo y lo articulará con el sinthome, considerado como saldo del levantamiento relativo de los síntomas; es decir, se parte del 
síntoma y se llega a un "núcleo incurable", un resto indescifrable. El sinthome queda vinculado a "un saber hacer ahí con eso", se trata de una sutura, un empalme; al respecto, Schejtman (2013) aporta que el sinthome es un remiendo, una corrección, una compensación, una suplencia, y que ese saber arreglárselas sinthomático nos mantiene más o menos estables, pero también más o menos adormecidos.

Lacan dirá que el sinthome es un acontecimiento de cuerpo. Así lo refiere en la conferencia "Joyce el síntoma": "Dejemos el síntoma en lo que es: un acontecimiento de cuerpo" (Lacan, 2012/1975, p.595).

¿Cómo se diferencian los conceptos de síntoma y sinthome? El síntoma, como formación del inconsciente, produce efectos de sentido por la sustitución del significante, implica una operación de desciframiento. El sinthome, en cambio, es un acontecimiento de cuerpo, una emergencia de goce, un cifrado que afecta al cuerpo, un goce opaco.

Caretto (Rollier et al., 2016) advierte que "acontecimiento" proviene del latín "advenire", que significa "venir a", e indica un evento de carácter inusitado que introduce una discontinuidad en la vida de un sujeto. Marca un antes y un después. Pessoa Gonzalvez plantea: "En el encuentro contingente del cuerpo con el significante, el goce es producido, excavando el cuerpo. Surge así el acontecimiento de cuerpo, una marca de goce derivada de este encuentro contingente" (Rollier et al., 2016: 144).

De este modo se pasa de la concepción del síntoma histérico de Freud y del síntoma del Otro en Lacan, al sinthome. El síntoma es lo analizable, el sinthome un goce opaco. El síntoma del parlêtre que Lacan define como acontecimiento de cuerpo, segrega al sujeto en el aislamiento de un imposible de decir (Rollier et al., 2016).

Miller en Biología lacaniana y acontecimiento del cuerpo (2002) aportará que si el síntoma es satisfacción pulsional, entonces siempre es acontecimiento de cuerpo. Siempre hay acontecimientos que dejan huellas en el cuerpo, huellas que perturban al cuerpo. Dichos acontecimientos tienen que ver con el significante, pero no produciendo efecto de significado, sino -referirá Miller- efecto de afecto en el cuer- 
po, goce; cuando se trata de efectos durables, permanentes, se los puede llamar huellas. Se trata aquí del cuerpo como sustancia gozante, tal como Lacan (1981/1972-1973) lo plantea en el Seminario 20.

A este modo de operar del significante (no articulándose, sino como una presencia), Miller lo denominará corporización, y dirá que es en cierto modo el revés de la significación. Es el significante afectando el cuerpo del ser hablante, despedazando al cuerpo hasta hacer surgir el goce. Hay que diferenciar, aclara Miller, la corporización codificada, normada, que proviene de un discurso y que inscribe el cuerpo en el vínculo social, de la corporización contemporánea donde el cuerpo tiende a ser descuidado por las normas, como en el caso de los piercings, body art y dictadura de la higiene.

Respecto al acontecimiento de cuerpo, otros autores, como André Vieira, dicen: "(...) este tipo de acontecimiento remite a algo en nuestro cuerpo que es hablante, incluso si no es discurso" (Brodsky et al., 2015, p.32); y agrega Bassols: "Porque hay parlêtre -el parlante-, hay palabra; hay la letra de la sustancia gozante que va a estar inscripta en el síntoma, que va a estar inscripta finalmente en el sinthome; y hay el ser" (Brodsky et al., 2015, p.80).

Miller (2002), por su parte aclarará que el síntoma como acontecimiento de cuerpo es altamente susceptible de ponerse en evidencia en la psicosis, pero puede contemplarse también en el marco de la neurosis.

\section{Época y marcas del cuerpo}

Suele plantearse que hay síntomas propios de cada época o síntomas que no se presentan con el mismo significado que en otras épocas. Por ejemplo, el tatuaje existe desde hace muchos años, pero a lo largo de la historia ha ido adquiriendo diferentes significados. El sujeto que llega a la consulta está inmerso en un contexto particular y en un momento determinado de la historia; el psicoanálisis no puede desconocer esto, Lacan lo expresa así: “Mejor pues que renuncie quien no 
pueda unir a su horizonte la subjetividad de su época" (2008/19531956, p.308). De este modo, Lacan invita a no quitar la mirada de la época cuando se trata del sujeto, sujeto que no puede pensarse en relación con diferentes acontecimientos de cuerpo sin pensarlo inserto en un determinado tiempo y lugar.

Ahora, hay un discurso contemporáneo que incide en el sujeto y en el lazo social, pero más allá de la incidencia de la época, desde el psicoanálisis se tiene en cuenta cada sujeto en su singularidad. La época actual posee ciertas características que sostienen un modo de gozar con el cuerpo que no pasa tanto por la articulación entre significantes, sino que prevalece el goce del Uno, autoerótico, un goce opaco. Una de esas características es el predominio de la virtualidad, donde la contemplación de la imagen cobra un valor significativo. El avance de la ciencia y de la tecnología, con sus nuevas técnicas, "posibilita" diferentes invenciones de corporización (Rollier et al., 2016): lo que el sujeto no tiene o no le gusta en su cuerpo lo puede agregar, cambiar, quitar, modificar, mejorar, controlar. Así la ciencia le dice que puede "tener un cuerpo", además le dice cómo hacerlo y también cómo debe ser ese cuerpo. Hay un avasallamiento del sujeto del deseo por la tecnología.

El avance tecnológico alienta, además, una cultura de la obsolencia (Cebolla Lasheras et al., 2012): las cosas rápidamente caen en desuso, son descartables, y la renovación permanente de objetos se vuelve un imperativo. De este modo se niega la pérdida y no se da lugar a los procesos de duelo. Estas condiciones, que llevan cada vez más a morder el anzuelo de la imagen, contribuyen a la negación de la falta estructural, quedando así la subjetividad, y con ella el deseo, arrasados por la época.

Lacan (1985/1966) plantea la existencia de una falla epistemosomática, que es aplicable a la época actual en relación al efecto que tiene el progreso de la ciencia sobre la relación entre el cuerpo y la medicina. Se trata de cuerpos estudiados, diagnosticados, medicados, quedando fuera la dimensión gozante. Sujetos que acuden al médico para que este los diagnostique, garantizando así la presencia de la enfermedad; pero ello no implica necesariamente la búsqueda de la curación, a veces oculta que el sujeto se aferra a un padecer. 
Si bien cada época aporta a la construcción de subjetividades, cada sujeto responde a ello desde su particularidad conforme sea su constitución subjetiva y su posición ante la castración; dependerá de cómo cada uno acepta la falta, la capacidad para tolerar las pérdidas, tramitar simbólicamente la angustia, soportar el dolor y elaborar duelos, trabajos propios del sujeto del deseo. Pero no todos los sujetos tienen dificultad para atravesar estos procesos, no todos responden ante las complicaciones de la vida marcando su cuerpo con ciertos avatares, ¿por qué, entonces, algunos lo hacen y otros no? Ello dependerá de los modos de gozar instalados en cada uno, trayectos pulsionales que han quedado facilitados, marcas de lalengua sobre ese cuerpo.

\section{Cuando la angustia marca el cuerpo. A propósito de dolores y duelos}

Estos avatares -acontecimientos de cuerpo- se manifiestan en cada sujeto de manera particular, única, y suelen tener detrás algún acontecimiento de vida. Cada sujeto entrevistado en esta investigación hizo referencia a alguno: "me tatué después que...", "apareció la enfermedad cuando...", pero ahí hay algo no dicho que tiene que ver con el goce, algo que no pasa por el sentido, el acontecimiento relatado es un hecho biográfico que no se enlaza a una articulación significante, quedando plasmado en una marca, un signo. Algo acontece en la vida de estos sujetos y resuena en el cuerpo poniendo en marcha un trayecto pulsional que traduce el silencio de la pulsión de muerte. Un real que no se deja metaforizar.

Freud dice claramente que esta pulsión se dedica a destruir su propia morada orgánica (1976/1933); se vuelca al propio cuerpo en un acto autopunitivo: somatizaciones, tatuajes, perforaciones, autolesiones, escarificaciones, aseguran la presencia del dolor, lo superyoico manda a gozar. No poder parar de tatuarse, de cortarse, de perforarse, es la voz del superyó.

Es la pulsión la que hace de este cuerpo un cuerpo hablante. Algo allí habla de forma misteriosa, enigmática, da cuenta de algo oculto, 
incomprensible; para ello Lacan (2006/1975) ofrece el término parlêtre, para pensar a este sujeto que habla a través de ese cuerpo.

Como analistas nada sabemos de este misterio; cómo escuchar, entonces, a un parlêtre, con un cuerpo que goza, que no produce sentido, que no quiere decir nada. Lacan (2006/1975) privilegió el orificio de la oreja, porque allí ingresan las palabras que pueden afectar la sustancia gozante provocando que algo resuene en ese cuerpo. Hay modos de gozar instalados en ese cuerpo a partir de palabras que dejaron marcas, tal vez nuevas palabras dichas y oídas puedan resonar allí produciendo un efecto simbólico.

Estas marcas -despojadas de una envoltura significante- dan cuenta de la presencia de un goce que deja por fuera el necesario atravesamiento de la angustia frente a ciertos acontecimientos de vida. La angustia queda así resguardada, encubierta por un tatuaje, un corte, una lesión psicosomática. ¿Por qué el sujeto evita vérselas con la angustia?, porque es un afecto que intranquiliza, conmociona, inquieta, estremece, turba.

Se trata de un afecto no tramitado que está desamarrado del significante y orienta al sujeto hacia una posición deseante; es un afecto que conduce al deseo, a modo de un sendero, dice Lacan (2006/19621963), pero es un camino algo desviado donde el sujeto puede descarrilarse, extraviarse, despistarse.

Como se advierte en estos testimonios, la angustia es un afecto no tramitado que está desamarrado del significante; orienta al sujeto hacia una posición deseante, es un afecto que conduce al deseo, a modo de un sendero, dice Lacan (2006/1962-1963), pero es un camino algo desviado, donde el sujeto puede descarrilarse, extraviarse, despistarse.

En la presente investigación se planteó como hipótesis que algunos sujetos que no logran tramitar la angustia por vía simbólica, marcan su cuerpo con ciertos avatares. Si la angustia fue definida por Freud (1976/1926) como una reacción frente a una situación de peligro, tramitarla implicará poder tolerar el mismo, el peligro será 
siempre la castración; si se trata de un afecto desamarrado, el sujeto deberá entonces intentar amarrar, anudar, articular algún significante; si la angustia implica soportar la proximidad del deseo del Otro, se deberá aceptar que el Otro está castrado, por ende el sujeto también lo está, y poder así moverse en la vida teniendo en cuenta la falta.

También la angustia se presenta cuando falta la falta (Lacan, 2006/1962-1963), cuando el sujeto está sumergido en un goce que lo aleja de la posición deseante. Para que el deseo pueda circular, será necesario hacer un movimiento hacia lo simbólico que sólo es posible si hay reconocimiento y aceptación de la falta. En los sujetos entrevistados se observó dificultad para poder tramitar simbólicamente la angustia, en su lugar aparecía algo que venía a marcar el cuerpo, un trayecto pulsional plasmado en la piel. Debido a la labilidad en el encadenamiento simbólico, se deja vía libre a otros modos de goce diferentes al síntoma.

Otro elemento observado en este trabajo es la presencia del dolor. En estas marcas el dolor suele cobrar cierto protagonismo. En estos avatares la piel es perforada, atravesada, de este modo se eleva la investidura narcisista y el lazo con el otro se debilita. Tatuarse, perforarse, lesionarse son prácticas que implican resistir al dolor. ¿De qué dolor se trata?; en algunos casos los sujetos entrevistados plantearon la dificultad para tolerar ciertos dolores, estas marcas aparecieron ante la presencia de pérdidas, de dificultades, instalándose un goce autoerótico plasmado en el cuerpo.

Cada marca sobre el cuerpo presenta su particularidad. El tatuaje es utilizado con diferentes finalidades, en algunos casos a modo de rito iniciático o bien marca identitaria, de pertenencia grupal, cobrando fundamentalmente un valor ritual significante. En otros casos la finalidad es generar fascinación y erotismo (valor imaginario), y en otras situaciones predomina su valor erógeno (observado predominantemente en los casos trabajados), a modo de un goce autoerótico que intenta velar la hiancia de la falta constitutiva del sujeto para quedar resguardado de esta última, el tatuaje penetra la piel y se aloja en ella de modo irreversible. 
En algunos casos esta marca se utiliza en un intento por simbolizar, tramitar la angustia, para poder elaborar pérdidas. El cuerpo va registrando, tomando nota de esas pérdidas. Algunos avatares que marcan el cuerpo pueden deberse a duelos que han quedado "suspendidos" en la vida del sujeto:

En relación con las autolesiones, estas suelen ser actos realizados en soledad, que se presentan ante episodios desencadenantes vividos con un gran aumento de tensión. También remiten a una angustia no tramitada, vivida como amenazante, una angustia insoportable ante la cual el sujeto no logra elaborar un saber para calmarse, en su lugar se utiliza el corte a modo de un "calmante", buscando generar un dolor más manejable y soportable. A diferencia del tatuaje y de los fenómenos psicosomáticos, la autolesión puede considerarse en algunos casos como un acting out (Kuras de Mauer y May, 2015), un llamado al Otro donde algo se da a ver. Hay un intento de instaurar un intervalo, un intento de inscripción y separación para que el sujeto pueda emerger, se busca que el corte asuma el efecto de una falta.

Los fenómenos psicosomáticos también dan cuenta de algo no tramitado. La enfermedad somática suele interrumpir manifestaciones psíquicas de la melancolía (Freud, 1976/1917), detiene así el dolor y la elaboración de duelos que conllevan un sufrimiento insoportable para el sujeto. De este modo progresa el ruido del cuerpo, que asume un exceso que no se pudo procesar, un goce específico se inscribe en él y el sujeto se desvanece. A diferencia del tatuaje, estas marcas entran al análisis derivadas y acompañadas de un diagnóstico y un tratamiento médicos. Estas marcas también pueden perforar, lesionar la piel; una forma de padecer es relevada por otra, reteniendo así cierto grado de padecimiento. De este modo se enlazan duelos patológicos y enfermedades somáticas. El sujeto enferma como consecuencia de la anulación de la subjetividad a partir de la solidificación de los significantes (holofrase) (Lacan, 1987/1964), perdiéndose el intervalo que aloja al sujeto.

Refiriéndose a lo psicosomático, Lacan (1988/1975) plantea que es algo ante lo cual los analistas a menudo nadamos, podríamos agregar que es algo ante lo cual a menudo naufragamos, algo que no se 
puede leer ni traducir; hacemos esto extensivo a los otros avatares mencionados, teniendo en cuenta que hay cierta labilidad en el encadenamiento simbólico. Será necesario buscar un significante que sea realmente un significante, para que algo resuene en ese cuerpo y pueda regularse algo de ese goce con el fin de producir un movimiento en los modos de presentación del sufrimiento. Para ello será necesario amarrar algo de la angustia, ya que es un afecto que va a la deriva; si bien la angustia es estructural, constitutiva y productiva, porque conduce al deseo, también puede arrasar con el sujeto cuando él mismo no puede tramitarla por la vía simbólica.

En algunas de estas marcas algo se anuncia en relación al deseo del sujeto, se anuncia que está impedido, obstaculizado, y que un trayecto pulsional está en marcha, encapsulado en un espacio, la piel, a modo de un museo. En un museo algo se guarda, o bien porque está por extinguirse o bien para resguardarlo, quedando allí sin movimiento y lejos de la angustia.

En estas marcas la mirada, como pulsión escópica, suele cobrar un lugar preponderante, hay un placer de ver, de verse y ser visto, se invoca la mirada, quedando allí el deseo del sujeto detenido, sin pasar al tiempo de comprender y al momento de concluir.

\section{Conclusiones}

En el análisis, estos avatares del cuerpo se hacen presente; si bien el analista siempre se las tiene que ver con un sujeto -no con los cuttings, tatuajes, piercings, enfermedades, ni con la curación de los mismas-, sí trabaja con un sujeto que tiene un cuerpo, pero un cuerpo diferente al abordado por la medicina, un cuerpo imaginario, un cuerpo mortificado por el significante, y fundamentalmente tendrá que considerar que se trata de un cuerpo en tanto sustancia gozante, donde habita un goce irreductible, un goce opaco al sentido.

Por lo tanto, no hay psicoanálisis sin cuerpo; como plantea Salman (Brodsky et al., 2015), las palabras y el cuerpo son materia prima 
de la experiencia analítica y ambos se anudan para dar vida al cuerpo hablante. Teniendo en cuenta esto, el analista tendrá que vérselas con las particularidades de ese padecimiento, ese acontecimiento en el que se encuentra apresado un sujeto que tendrá que trabajar para no quedar en la fatalidad de ese goce intentando nuevos anudamientos, haciendo un nuevo uso en el registro del goce.

Para la clínica psicoanalítica no es el fenómeno lo que podría responder por el sujeto, solo el significante que emerge bajo transferencia daría cuenta de la manera como un sujeto se hace representar, manera que, además, debe ser producto del mismo paciente. Se trata de la apuesta por el desciframiento a través de la palabra del paciente en un intento de construir un saber.

Cada uno tiene una relación particular con el propio cuerpo. El modo de goce siempre es singular, único. El análisis deberá tener en cuenta que hay algo del orden de lo indescifrable, deberá entonces centrarse en el saber hacer de cada parlêtre para que pueda buscarse la regulación de un goce diferente.

Para concluir, retomo las palabras de Freud, quien nos invita no sólo a escuchar a nuestros pacientes, sino también a mirarlos para poder escucharlos: "El que tenga ojos para ver y oídos para oír se convencerá de que los mortales no pueden guardar ningún secreto. Aquel cuyos labios callan, se delata con la punta de los dedos; el secreto quiere salírsele por todos los poros" (1976/1905, p.68, énfasis mío).

\section{Referencias bibliográficas}

Brodsky, G., Bassols, M., Vieira, M. A., Salman, S., Tendlarz, S., Baudini, S., ... Simonetti, A. (2015). El cuerpo hablante. Parlêtre, sinthome, escabel. Buenos Aires, Argentina: Grama.

Castelluccio, C. (2013). El fenómeno del tatuaje: nombre propio y escritura. Buenos Aires, Argentina: Letra viva.

Cebolla Lasheras, M. J., Fortuny, P., Mandet, E., Romano, A. y Weintraub, E. (2012). El tatuaje, un enigma a ser descifrado: Ensayo psicoanalítico. Buenos Aires, Argentina: Letra Viva. 
Freud, S. (1976/1905). Tres ensayos de teoría sexual. En J. Strachey (Ed.), Obras completas (J. L. Etcheverry, Trad., Vol. VII). Buenos Aires, Argentina: Amorrortu.

Freud, S. (1976/1915). Pulsiones y destinos de pulsión. En J. Strachey (Ed.), Obras completas (J. L. Etcheverry, Trad., Vol. XIV). Buenos Aires, Argentina: Amorrortu.

Freud, S. (1976/1917). Duelo y melancolía. En J. Strachey (Ed.), Obras completas (J. L. Etcheverry, Trad., Vol. XIV). Buenos Aires, Argentina: Amorrortu.

Freud, S. (1976/1923). Dos artículos de enciclopedia: Psicoanálisis y teoría de la libido. En J. Strachey (Ed.), Obras completas (J. L. Etcheverry, Trad., Vol. XVIII). Buenos Aires, Argentina: Amorrortu.

Freud, S. (1976/1926). Inhibición, síntoma y angustia. En J. Strachey (Ed.), Obras completas (J. L. Etcheverry, Trad., Vol. XX). Buenos Aires, Argentina: Amorrortu.

Freud, S. (1976/1933). Nuevas conferencias de introducción al psicoanálisis. En J. Strachey (Ed.), Obras completas (J. L. Etcheverry, Trad., Vol. XXII). Buenos Aires, Argentina: Amorrortu.

Kuras de Mauer, S., y May, N. (2015). Cortarse solo: Acerca de las autolesiones en la piel. Controversias en Psicoanálisis de Niños y Adolescentes, 16. Recuperado de http://www.controversiasonline.org.ar/PDF/anio2015n16/1-MAUER-ESP.pdf

Lacan, J. (1973-1974). Seminario 21: Los incautos no yerran (los nombres del padre). Versión íntegra. Recuperado de http://www.bibliopsi.org/docs/ lacan/26\%20Seminario\%2021.pdf

Lacan, J. (2008/1953-1956). Función y campo de la palabra y del lenguaje en psicoanálisis. En Escritos 1 (pp. 231-309). Buenos Aires, Argentina: Siglo Veintiuno Editores.

Lacan, J. (1981/1968-1969). El Seminario Jacques Lacan. Libro 16: De un Otro al otro. Buenos Aires, Argentina: Paidós.

Lacan, J. (1985/1966). Psicoanálisis y medicina. En Intervenciones y textos 2. Buenos Aires, Argentina: Manantial.

Lacan, J. (1987/1964). El Seminario Jacques Lacan. Libro 11: Los cuatro conceptos fundamentales del psicoanálisis. Buenos Aires, Argentina: Paidós.

Lacan, J. (2008/1966). La agresividad en psicoanálisis. En Escritos 1 (pp. 107128). Buenos Aires, Argentina: Siglo Veintiuno Editores.

Lacan, J. (1988/1966-1967). La lógica del fantasma. En Reseñas de enseñanza. Buenos Aires, Argentina: Manantial.

Lacan, J. (2008). El estadio del espejo como formador de la función del yo (je) tal como se nos revela en la experiencia psicoanalítica. En Escritos 1. ( ${ }^{\circ}$ ed.) (pp. 99-106). Buenos Aires: Siglo Veintiuno Editores. 
Lacan, J. (1988/1967). Del psicoanálisis en sus relaciones con la realidad. Intervenciones y textos 2. Buenos Aires, Argentina: Manantial.

Lacan, J. (1981/1972-1973). El Seminario Jacques Lacan. Libro 20: Aún. Buenos Aires, Argentina: Paidós.

Lacan, J. (1988/1975). Conferencia en Ginebra sobre el síntoma. Intervenciones y textos 2. Buenos Aires, Argentina: Manantial.

Lacan, J. (2006/1962-1963). El Seminario Jacques Lacan. Libro 10: La angustia. Buenos Aires, Argentina: Paidós.

Lacan, J. (2006/1975). El Seminario de Jacques Lacan. Libro 23: El sinthome. Buenos Aires, Argentina: Paidós.

Lacan, J. (2012/1975). Otros escritos. Buenos Aires, Argentina: Paidós.

Miller, J. A. (2002). Biología lacaniana y acontecimiento del cuerpo. Buenos Aires, Argentina: Edigraf.

Miller, J. A. (2013). Hablar con el cuerpo. vi Encuentro Americano de Psicoanálisis de la Orientación Lacaniana, XVIII Encuentro Internacional del Campo Freudiano. Recuperado de http://www.enapol.com/es/template. php?file=Argumento/Conclusion-de-PIPOL-V_Jacques-Alain-Miller.html

Rollier, F., Miller, J. A., Laión, A., Ratier, F., Morao, M., Pelliza, M., ... Ramírez, C. (2016). El cuerpo hablante. Sobre el inconsciente en el siglo XxI. x Congreso de la Asociación Mundial de Psicoanálisis. Rio de Janeiro, Brasil: Grama.

Salman, S. (2013). El cuerpo en la experiencia del análisis. Boletín Colofón. Cuerpos que hablan, 33, 7-17. Buenos Aires, Argentina: Grama.

Schejtman, F. (2013). Sinthome, ensayos de clínica psicoanalítica nodal. Argentina: Grama.

Vittar, H. (2014). El cuerpo del analista, herramienta fuera de serie. Enigmas del cuerpo, revista de psicoanálisis, 5(5), 45-46. 